\title{
Study on Interior Design and Architectural Culture
}

\author{
Haoran Yang \\ Environmental art college, Hebei Academy of Fine Arts, Shijiazhuang, \\ 050700, China
}

\begin{abstract}
Over 5,000 years of development, traditional Chinese architectural culture has formed unique style and concepts and has been affecting architectural style and interior design of neighboring countries since feudal society. Along with dramatic impacts of western culture on traditional Chinese culture after the reform and opening up, however, traditional Chinese architectural culture can no longer have an influence on neighboring countries and is even ignored by China itself to a certain extent, so that traditional architectural culture loses vitality. Fortunately, with increasingly higher position of China in the world at current stage, traditional architectural culture is again attached importance to, and many contemporary interior designers combine traditional architectural culture with modern interior design concepts, which not only inherit and develop China's traditional architectural culture, but also make modern Chinese interior design form a new fashion style and promote the development of modern interior design. This paper firstly introduces interior design and architectural culture as well as their relationship briefly, and then discusses about inheritance of architectural culture in interior design. Hopefully, traditional and modern interior design can be truly combined in modern Chinese interior design to form a unique style.
\end{abstract}

Key words: interior design, architectural culture, inheritance, application

In previous years, Chinese politics, economy and culture are affected by cultures of countries in the world with the acceleration of economic globalization. Particularly, Chinese interior design concepts are seriously influenced by western culture, and national culture and regional characteristics are constantly weakened and marginalized, so that traditional Chinese architectural culture loses its 
survival soil and faces difficulties in both inheritance and development. In recent years, however, traditional Chinese culture is increasingly recognized and concerned by international community, and designers from all walks of life have begun to introduce traditional culture to modern construction, and thus elements of traditional culture can be seen everywhere such as clothing, tableware and large municipal buildings. In such a context, Chinese interior design industry also combines traditional architectural culture with design concepts to have important influence on interior design, and even begins to get rid of its dependence on western design concepts, gradually forms a design mode with its own characteristics and will create a new situation of Chinese interior design.

\section{Interior design and architectural culture}

(I) Concept of interior design

Modern interior design is an inevitable outcome of development of architectural movement based on modernist ideas to a certain stage, and is a new industry separated from architectural industry. It has intimate relations with traditional architectural industry, arts and environmental cause in terms of design concept, construction and objectives, and even has interdisciplinary relations with traditional architectural industry both theoretically and practically. For the concept of interior design, scholars from different schools have slightly different specific description out of their different recognition and researches of interior design, but all of these concepts are unanimous in nature. Interior design refers to a rational creation activity, in which subjects of interior design grasp and create interior building space using interior design concepts and materials \& technologies according to the environment and actual functions of interior space to make such functions applicable, beautiful and comfortable so as to meet people's physical and psychological needs. Thus, to put it simply, interior design is a specific creation process with the core of interior building space, processing and combination of life and arts, "ontology" of human spiritual needs and "function" of material needs.

(II) Connotation of architectural culture 
Traditional Chinese architectural culture has a long history, and came into being as early as in primitive society. Over nearly 1,000 years of development, it was relatively mature in Sui and Tang dynasties, and forms a quite complete cultural system today with profound influence on architectural design of both modern China and the world. Traditional culture generally refers to an aggregate of relatively stable cultural connotation over long-term accumulation and inheritance, and covers almost the sum of all material and spiritual cultures including basic knowledge, customs, ideology and morality, legal system, value system, living habits and lifestyles etc handed down from history of the nation. As a relatively independent individual in the whole cultural system, architectural culture has all properties and characteristics of traditional culture, and is not just a simple cultural form, but also a cultural carrier which carries all spiritual ideas and material forms closely related to buildings in the past and at present and reflects material and spiritual properties of architectural culture.

(III) The relationship between interior design and architectural culture

Interior design is closely related to architectural culture, as it stems from architectural design, develops constantly with increasingly growing architectural industry, and shows elaboration and extension of architectural design. Besides, interior design represents people's spiritual characteristics and pursuit to a certain degree as it mainly designs interior space to meet people's physical, psychological and practical environmental needs. Interior design generally consists of two aspects: firstly, design of interior space shall meet use functions of space itself, maximize reflection of the will of designers in terms of both environment and property, and cater generally to characteristics of the times in terms of people's psychological pursuit; and secondly, people's spiritual pursuit shall be considered in interior design in terms of expression of spiritual characteristics. As people's spiritual pursuit closely relates to their values, aesthetics, aesthetic needs and national cultural identity, traditional architectural culture and concept of interior design share a lot of similarities from these aspects, and can be combined in terms of thought and spirit to promote mutual 
development. However, although traditional architectural culture is stable to a certain degree over long-term accumulation, not all of its concepts could adapt to development needs of modern interior design as some cultures have strong characteristics of the times, and mandatory introduction would only lead to collision and conflicts of both cultures and finally result in no social recognition of interior design. So, the relationship between traditional culture and modern interior design shall be correctly understood in order to introduce traditional cultural concepts scientifically and rationally and promote better development of interior design.

\section{Inheritance of traditional architectural culture in modern interior design}

With continuous economic development in China, people's living standard is gradually improved and higher requirements are proposed for interior design. With increasingly abundant material life, people's living environment is no longer confined to simple need of keeping out wind and rain, but pursues a higher level of living space which can meet both material and spiritual life. So, modern interior design industry emerges under strong social demand to design interior building space in order to improve people's living standard. However, with a late start and absence of good guidance or standardization at the beginning, Chinese interior design industry has common plagiarism, and can hardly form its own unique style although it combines interior design thoughts and concepts of countries in the world. Fortunately, traditional Chinese architectural culture has unique characteristics and systematic style \& system in world history of architectural culture. Thus, to better develop interior design industry and integrate traditional architectural culture with Chinese interior design concepts, exploration of integrating traditional architectural culture with interior design shall be strengthened continuously so as to truly inherit and develop traditional architectural culture in modern interior design.

Firstly, modern interior design shall inherit and develop thoughts of nature and harmony in traditional culture. The application of natural landscapes in traditional Chinese architectural culture is highly worshiped. Design of most of 
buildings with high achievements contains a lot of natural elements which are given extremely important cultural connotation, solemn or auspicious or lively, reflecting the thought of harmony between man and nature. Modern interior design inherits concepts of traditional architectural culture, applies a large amount of natural landscapes to background shaping and key decoration of interior design, and achieves interactive integration of interior natural environment with humanistic thoughts, in order to meet people's spiritual needs.

Secondly, thought of combination of rites and music in traditional architectural culture shall be of human-oriented development. Traditional Chinese culture is actually people-oriented in a sense, and has direct influence on traditional Chinese architectural concepts. Firstly, humanistic thought of Confucianism has an influence on spatial construction forms and aesthetic standards of architectural design. Confucianism culture stresses rites \& music and ethnic education of heaven $\&$ earth and emperor \& ministers etc, and so architectural design has often an architectural layout based on the order of heaven \& earth and Yin \& Yang and emphasizes particularly on primary and secondary levels of buildings. Secondly, pursuit of superiors \& inferiors and balance in traditional Confucianism thought of rites and music leads to traditional architectural system, which builds based on principal axis, stresses grammatical principles of principal axis and focuses on irregularity of other lines. Traditional Chinese combined courtyards follow this thought and build the most revered buildings on the principal axis, which fully shows the relationship between superiors and inferiors and symmetrical beauty of buildings. Modern interior design shall also inherit and develop this thought, and make appropriate judgment while inheriting according to practical situation in order to make this concept adapt more to needs of modern interior design and truly reflect characteristics of modern Chinese interior design.

Finally, inheritance of traditional architectural culture shall follow the all-embracing principle. Traditional Chinese architectural culture is extensive and profound with a long history and can be referred to by modern architectural 
design from many aspects. However, with global economic and cultural development and acceleration of modernization, foreign architectural design concepts have impacts on traditional Chinese architectural culture, and affect the inheritance of traditional architectural concepts in and development of modern Chinese architectural design. Undeniably, Chinese interior design industry can still worship and refer to these concepts a lot although foreign design concepts are not as numerous and systematic as Chinese ones, and there are still some concepts that cannot adapt to development needs of modern interior design no matter how extensive and profound traditional Chinese architectural culture is. Thus, inheritance of traditional culture shall adhere to the all-embracing principle to learn from strengths and avoid weaknesses for better development.

\section{Application of traditional architectural culture in modern interior design}

With gradual concern of traditional Chinese architectural culture in society and the entire international design industry in recent years, China begins again to introduce elements of traditional culture to architectural design, inherits and makes innovation of traditional culture by combining with modern design concepts. In particular, a large number of modern interior designers have designed a series of works with characteristics of both the times and traditional architectural culture based on Chinese culture, exceeding traditions and all-embracing principle, causing huge impacts on modern Chinese interior design. For instance, international trade centers, arts and crafts museums, and Shanghai Grand Theatre etc built in recent years are representatives of modern interior design by Chinese designers based on inheritance of traditional architectural cultural concepts, and reflect modern Chinese interior design level. These successful interior designs combine traditional architectural concepts with advanced foreign design concepts and decoration technologies based on inheritance of traditional architectural culture of this nation, and are both novel

and culturally artistic, and would be the development direction of interior design industry in future China. However, inheritance and development of traditional culture in Chinese interior design are not confined to these classical works, and 
elements of traditional architectural culture are integrated in modern interior design from many aspects, and unique style of Chinese interior design is gradually coming into being.

Firstly, modern Chinese interior design has begun to refer to philosophical thoughts of traditional architectural culture. Traditional Chinese culture affects art design by influencing people's consciousness, so that Chinese art designers would introduce the concept of natural harmony in traditional culture subconsciously during design, and often unexpected effects would be achieved. For example, Pei Leoh Ming introduces thoughts of Moral Classics to design of Suzhou Museum, combines space concept in this book with interior design, and gives people unique aesthetic enjoyment.

Secondly, elements of traditional architectural design are introduced to modern interior design. Over several thousand years of development, Chinese garden construction shows a trend to be classical in terms of architectural design, landscape design, interior design and setting. For example, decorative elements such as Guqin, calligraphy, ceramics, traditional Chinese paintings, embroidery and murals etc show the quiet and elegant style of classical culture, while interior structural elements such as screens, hanging screens and partition boards etc also show the application of traditional culture in spatial layout. Modern designers apply these elements to interior design, and build new structures and decoration in traditional cultural elements. This is of practical significance, as it shows both inheritance of traditions and development of modern design.

Finally, modern interior design applies symbols of traditional architectural culture to interior decoration. Over prolonged accumulation, traditional Chinese architectural culture forms a large number of graphic decorations with Chinese cultural connotation. For example, Chinese paintings and calligraphy, a variety of traditional emblazonry patterns (auspicious cloud patterns, strange animal patterns and could thunder patterns etc), carvings and totems etc generally have profound cultural connotation and even symbolic meanings. Modern interior design applies these traditional cultural symbols to interior decoration, creates a 
traditional cultural atmosphere in interior space of modern buildings, and forms unique aesthetic enjoyment.

\section{Conclusions}

To sum up, architectural culture is closely related to interior design. To combine traditional architectural culture with modern interior design, designers shall reflect profoundly on traditional Chinese history and culture, analyze and extract traditional cultural concepts according to modern design needs, learn from foreign interior design concepts, and combine foreign and domestic concepts organically, in order to better promote the development of modern design and strive to create a new situation of modern Chinese interior design as soon as possible.

\section{References:}

[1] Xu Ming. Analysis of Inheritance of Architectural Culture in Interior Design [J]. Building $\cdot$ Materials $\cdot$ Decoration, 2014 (11).

[2] Wan Guo. Inheritance and Development of Traditional Architectural Culture in Contemporary Interior Design [J]. Guide of Sci-tech Magazine, 2013 (10).

[3] Ou Yangfang. Integration and Application of Traditional Chinese Culture in Modern Interior Design [J]. Times Literature, 2010 (6). 